\title{
Computerized texture analysis of atypical immature myeloid precursors in patients with myelodysplastic syndromes: an entity between blasts and promyelocytes
}

\author{
Joyce R Vido ${ }^{1}$, Randall L Adam², Irene GH Lorand-Metze ${ }^{1}$ and Konradin Metze (* $^{*}$
}

\begin{abstract}
Background: Bone marrow (BM) blast count is an essential parameter for classification and prognosis of myelodysplastic syndromes (MDS). However, a high degree of cell atypias in bone marrow hemopoietic cells may be found in this group of clonal disorders, making it difficult to quantify precisely myeloblasts, and to distinguish them from promyelocytes and atypical immature myeloid precursors. Our aim was to investigate whether computerized image analysis of routine cytology would help to characterize these cells.

Methods: In May-Grünwald-Giemsa stained BM smears of 30 newly diagnosed MDS patients and 19 cases of normal BM, nuclei of blasts and promyelocytes were digitalized and interactively segmented. The morphological classification of the cells was done by consensus of two observers. Immature granulocytic precursors, which could not be clearly classified either as blasts or promyelocytes, were called "atypic myeloid precursors". Nuclear morphometry and texture features derived from the co-occurrence matrix and fractal dimension (FD) were calculated.
\end{abstract}

Results: In normal BM, when compared to myeloblasts, nuclei of promyelocytes showed significant increase in perimeter and local texture homogeneity and a decrease in form factor, chromatin gray levels, Haralick's entropy, inertia, energy, contrast, diagonal moment, cluster prominence, the fractal dimension according to Minkowski and its goodness-of-fit. Compared to normal myeloblast nuclei, the chromatin texture of MDS myeloblasts revealed higher local homogeneity and goodness-of-fit of the FD, but lower values of entropy, contrast, diagonal moment, and fractal dimension. The same differences were found between nuclei of normal promyelocytes and those of MDS. Nuclei of atypical myeloid precursors showed intermediate characteristics between those of blasts and promyelocytes according to the quantitative features (perimeter, form factor, gray level and its standard deviation), but were similar to promyelocytes according to the texture variables inertia, energy, contrast, diagonal moment, cluster prominence, and Minkowski's fractal dimension.

Conclusion: BM atypical immature myeloid precursors are difficult to be correctly classified in routine cytology. Although their cytoplasm is more similar to that of myeloblasts, computerized texture analysis indicates a nuclear chromatin remodeling more close to the promyelocyte, thus indicating an asynchronous intermediate maturation stage between blast and promyelocyte.

Keywords: myelodysplastic syndromes, bone marrow, nuclear texture, cell atypias, karyometry, morphometry, fractal, chromatin, co-occurrence matrix, computerized pathology

\footnotetext{
* Correspondence: kmetze@fcm.unicamp.br

${ }^{3}$ Department of Pathology, Faculty of Medical Sciences, State University of

Campinas, Rua Tessalia Vieira de Camargo 126, 13083-887, Campinas, Brazil

Full list of author information is available at the end of the article
} 


\section{Background}

Myelodysplastic syndromes (MDS) are a group of hemopoietic clonal disorders characterized by peripheral blood cytopenias and a cellular bone marrow (BM) showing cell atypias that reflect abnormalities in proliferation, maturation and apoptosis of hemopoietic precursors [1-6]. According to $\mathrm{WHO}$ criteria [7-9] the percentage of blasts counted in BM cytology is an essential parameter for diagnosis and classification of the several types of MDS, as well as for the differential diagnosis between refractory anemia with excess of blasts (RAEB) and acute myeloid leukemia. In normal hemopoiesis, strict morphological criteria can easily be used to define each stage of cell maturation, but in MDS, immature cells presenting an asynchronous maturation may often be difficult to classify [4,6-9]. Standardized morphologic criteria have been recommended [8,9] in order to separate MDS blasts and MDS promyelocytes. Yet, there is always some degree of subjectivity, although the FAB Group [1] and the International Working Group on MDS [8,9] had defined classification criteria, which were also included in the 2008 WHO classification [7]. Moreover, the European LeukemiaNet published in the Internet a consensus-based cell library elaborated by experienced morphologists $[8,9]$ that could be used as a guide for daily work and training. Despite of these efforts, the morphologic diagnosis continues to be a difficult task, and the morphologic diagnosis of MDS should only be done by a consensus of two expert morphologists $[3,6]$.

In cytological bone marrow smears of MDS patients, some immature cells may not be classifiable in a satisfactory way, because they show simultaneously characteristics of blasts and promyelocytes, thus not fulfilling the criteria of either category. This problem is known to the practicing hematologist, but, surprisingly not discussed in the scientific literature.

In recent years, virtual microscopy and computerized image analysis gained increasing importance [10-14]. These techniques have been widely used in pathology and cytology for the differentiation of normal cells, benign and malignant tumors [15-17], as prognostic markers in malignancy [18-20] and in order to examine chromatin remodeling of cells in culture after incubation with carcinogens [21], hormones [22] and therapeutic agents $[23,24]$. Computerized image analysis has shown to be a fast and reliable way for quantitative morphologic analysis $[10,18,19,25-28]$, and moreover, to be a possibility to detect subtle morphologic changes which cannot be recognized by conventional microscopy even by an expert.

The aim of the present study was to examine whether computerized nuclear texture analysis could help to characterize in a more objective way the blasts and promyelocytes in normal bone marrow, as well as in patients with MDS. We also wanted to examine if this technology was able to classify atypical immature myeloid cells present in bone marrow smears of these patients.

\section{Methods}

\section{Patients}

Routinely May-Grünwald-Giemsa-stained bone marrow (BM) slides from 19 morphologically normal bone marrows and from 30 consecutive cases of MDS were used for this analysis. Morphologically normal BM smears (control group) were obtained from the diagnostic work-up of patients with idiopathic thrombocytopenic purpura, with hypersplenism, and non-Hodgkin's lymphoma without bone marrow involvement. The diagnosis of MDS was based on the presence of sustained peripheral (PB) cytopenias, cell atypias in BM cytology and BM cytogenetics according to WHO 2008 criteria [7-9].

This project was approved by the Ethic's Comitee of our Institution (Proc 0652.0.146.000-08).

\section{Image analysis}

At least 30 consecutive nuclei of each type of immature granulocytic precursors (myeloblasts and promyelocytes) per patient were analyzed. Cells were classified by two independent experts (JRV and ILM) according to the criteria of the European Leukemianet Project [9] (Figure 1). We considered as "atypical immature myeloid precursors" (Figure 1C) cells without cytoplasmic Golgi apparatus, but with nuclear characteristics resembling more mature cells than myeloblasts, and that did not fulfill the proposed criteria for classification $[8,9]$.

Cell images were captured by a Leica DC 500 digital system (bmp-format; sample spacing of $0.1 \mu \mathrm{m} /$ pixel, 1.25 numerical aperture, 100x oil immersion objective). The nuclear images were interactively segmented, converted to grayscale format with gray levels ranging between 0 and 255 (being 255 the brightest). We examined variables of geometric morphometry such as nuclear area, form factor, mean gray level, and standard deviation of gray values. We also calculated texture features derived from the cooccurrence matrix $[17,27,28]$ and the fractal dimension (FD) according to Minkowski-Bouligand after pseudo-3D transformation $[18,20]$, as well as its goodness of fit $\left(R^{2}\right)$ $[19,20,29]$.

\section{Statistical analysis}

We compared the values obtained for normal myeloblasts and promyelocytes for all nuclear morphometric and texture features using the t-test for paired values. Student's t-test was used to compare morphometric and texture features of normal and MDS blasts and of normal and 

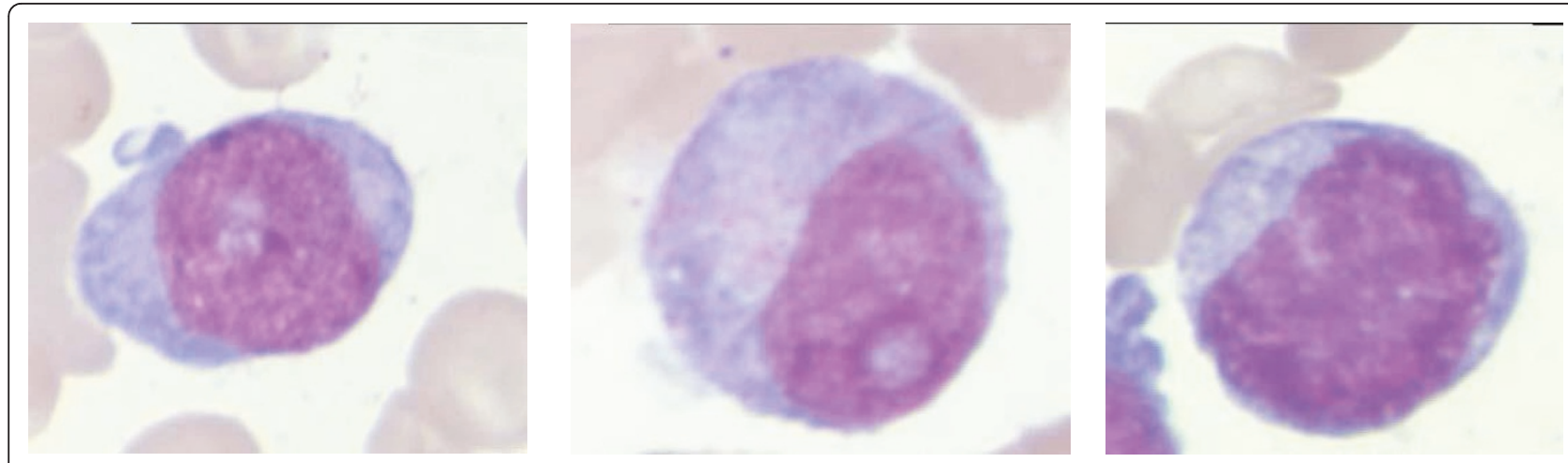

Figure 1 Immature granulocytic precursors observed in the MDS cases. A: myeloblast. B: promyelocyte. C: atypical immature granulocytic precursor. May-Grünwald-Giemsa ×1000.

MDS promyelocytes. In a third step, the differences between features of blasts, promyelocytes and atypical myeloid precursors of MDS patients were calculated by analysis of variance for repeated measures. Differences between blast and atypical myeloid precursors or between the latter and promyelocytes were calculated with the help of t-tests for paired values.

For every nuclear morphometric or texture feature we tried to find out whether the values of the atypical myeloid precursors were more similar to those of MDS-blasts (no significant difference between atypical precursors and blasts, but between atypical precursors and promyelocytes), or MDS-promyelocytes (significant difference between blasts and atypical precursors but no significant difference between atypical precursors and promyelocytes). A nuclear characteristic was considered to be "intermediate" between MDS-blasts and MDS-promyelocytes, when significant differences were found both between MDS-blasts and atypical precursors and between atypical precursors and MDS-promyelocytes. A variable was called "not defined", when the global test or both dependent $\mathrm{t}$-tests were not significant $(\mathrm{p}>0.05)$.

\section{Results}

Diagnostic smears from 19 normal BM and 30 cases of MDS were examined. Median age of the patients with normal BM was 57 years $(24-85 ; 9$ males and 10 females). The median age of the MDS patients was 64 years $(30-85)$. There were 16 males and 14 females (Table 1). According to the WHO type, most cases were RCMD (refractory cytopenia with multilineage dysplasia) and RAEB (refractory anemia with excess of blasts).

In normal BM, nuclei of promyelocytes showed significant changes, such as an increase of perimeter and local texture homogeneity and a decrease in form factor, chromatin gray levels, Haralick's entropy, inertia, energy, contrast, diagonal moment, cluster prominence, Minkowski's fractal dimension and its goodness-of-fit when compared with that of normal blasts (Table 2).
Compared to normal myeloblast nuclei, chromatin texture of MDS blasts had a higher local homogeneity as well as goodness-of-fit of the fractal dimension, but a lower entropy, contrast, diagonal moment, and fractal dimension (Table 3). Nuclei of promyelocytes from MDS showed a larger nuclear area, local homogeneity and goodness-of-fit of FD, but lower inertia, entropy, energy, contrast, diagonal moment and FD than normal ones (Table 4).

The values obtained for nuclei of granulocytic precursors in MDS are presented in Table 5.

Nuclei of atypical myeloid precursors showed intermediate characteristics between those of blasts and promyelocytes according to the quantitative features perimeter, form factor, gray level and its standard deviation, but were similar to promyelocytes according to the texture variables inertia, energy, contrast, diagonal moment, cluster prominence and Minkowski's fractal dimension. None of the features studied showed closeness to myeloblasts. These findings were independent of the WHO type of MDS.

\section{Discussion}

In recent years, computerized image analysis has been widely used in histology and cytology in order to examine tissue differentiation, for tumor classification

\section{Table 1 Age and hematological data of the MDS cases} (median)

\begin{tabular}{lccc}
\hline WHO type & RA/RARS* & RCMD $^{* *}$ & RAEB $^{* * *}$ \\
\hline Number of cases & 4 & 15 & 11 \\
Age (years) & 64 & 64 & 62 \\
Hemoglobin $(\mathrm{g} / \mathrm{dL})$ & 10.5 & 10.3 & 8.1 \\
PB leukocytes $\left(\times 10^{3} / \mathrm{mm}^{3}\right)$ & 4.7 & 3.6 & 3.1 \\
PB platelets $\left(\times 10^{3} / \mathrm{mm}^{3}\right)$ & 234 & 240 & 184 \\
BM Blasts $\%$ & 2.0 & 1.0 & 8.0 \\
\hline
\end{tabular}

* RA/RARS = refractory anemia/sideroblastic anemia; ${ }^{* *}$ RCMD = refractory cytopenia with multilineage dysplasia; ${ }^{* *}$ RAEB = refractory anemia with excess of blasts 
Table 2 Mean values of the variables obtained for normal granulocytic precursors

\begin{tabular}{|c|c|c|c|}
\hline & Blasts & Promyelocytes & $P$ \\
\hline Area $\mu^{2}$ & 111.9 & 112.7 & 0.75 \\
\hline Perimeter & 579 & 636 & $<0.0001$ \\
\hline Form factor & 0.957 & 0.792 & $<0.0001$ \\
\hline Mean gray level & 129.3 & 120.8 & $<0.0001$ \\
\hline SD gray level* & 8.6 & 8.1 & 0.04 \\
\hline Haralick's entropy & 7.90 & 7.77 & 0.02 \\
\hline Inertia & 4.17 & 3.82 & $<0.0001$ \\
\hline Local homogeneity & 0.535 & 0.538 & 0.51 \\
\hline Energy & 7177 & 6430 & $<0.0001$ \\
\hline Contrast & 4.17 & 3.82 & 0.005 \\
\hline Diagonal Moment & 19.1 & 17.7 & $<0.0001$ \\
\hline Cluster prominence & 3.38 & 2.79 & 0.01 \\
\hline FD** Minkowski & 2.134 & 2.128 & 0.08 \\
\hline$R^{2 * * *}$ & 0.99647 & 0.99613 & 0.007 \\
\hline
\end{tabular}

$[11,12,15-17]$ and for the search of new prognostic variables in neoplasias [18-20]. This approach has also been used in basic research for analyzing nuclear texture changes that reflect chromatin remodeling of cells after incubation with carcinogens [21], hormones [22] and therapeutic agents $[23,24]$.

Chromatin remodeling, which is primarily due to epigenetic events, can be found during cell differentiation or malignant transformation $[20,21,23,24,26]$. In normal hemopoiesis, gene expression during normal cell maturation is controlled by genetic and epigenetic changes [30]. Blast cells in acute myeloid leukemia and MDS always present epigenetic abnormalities and their DNA methylation signature is different to that of any stage of normal myeloid maturation, an observation which permits to distinguish normal and leukemic blasts [30-33].

In the present study we examined the utility of computerized chromatin texture analysis for the diagnosis of normal and atypical immature myeloid precursors in

Table 3 Mean values of the variables that differed in normal myeloblasts and those of MDS

\begin{tabular}{lccc}
\hline & Normal & MDS & $\boldsymbol{p}$ \\
\hline Haralick's entropy & 7.90 & 7.65 & 0.01 \\
Inertia & 4.17 & 3.67 & 0.05 \\
Local homogeneity & 0.535 & 0.553 & 0.01 \\
Energy & 7177 & 6749 & $\mathrm{n} . \mathrm{s}$ \\
Contrast & 4.17 & 3.67 & 0.05 \\
Diagonal moment & 19.1 & 17.4 & 0.05 \\
FD Minkowski * & 2.134 & 2.122 & 0.01 \\
$\mathrm{R}^{2 * *}$ & 0.99647 & 0.99819 & $<0.005$ \\
\hline
\end{tabular}

${ }^{*} \mathrm{FD}=$ fractal dimension. ${ }^{*} \mathrm{R}^{2}$ goodness-of-fit of the fractal dimension.
Table 4 Mean values of the variables that differed in normal promyelocytes and those of MDS

\begin{tabular}{lccc}
\hline & Normal & MDS & $\boldsymbol{p}$ \\
\hline Haralick's entropy & 7.77 & 7.52 & 0.03 \\
Inertia & 3.82 & 3.28 & 0.01 \\
Local homogeneity & 0.538 & 0.558 & 0.01 \\
Energy & 6430 & 5595 & 0.04 \\
Contrast & 3.82 & 3.28 & 0.01 \\
Diagonal moment & 17.7 & 15.6 & 0.02 \\
FD Minkowski & 2.128 & 2.118 & 0.03 \\
$\mathrm{R}^{2}{ }^{* *}$ & 0.99613 & 0.99809 & 0.001 \\
\hline${ }^{*} \mathrm{FD}=$ fractal dimension. ${ }^{*} \mathrm{R}^{2}$ goodness-of-fit of the fractal dimension.
\end{tabular}

routine BM smears. In normal BM, all except three of the quantitative features examined, presented significant differences between blasts and promyelocytes. Thus, chromatin texture analysis in routine BM cytology is able to define cells in early stages of myeloid maturation.

In MDS, genetic and epigenetic alterations provoke abnormalities of proliferation, maturation, and apoptosis [5,6,32-34], which, of course, are reflected in subtle alterations of the chromatin structure. The expression of various lineage and maturation-related membrane proteins may be discordant in granulopoietic precursors [32-34] provoking also morphological atypias. All these alterations hamper the cell classification. The difficulties in classify several cases with MDS are well known. The European LeukemiaNet created a consensus-based cell library elaborated by experienced morphologists and downloaded it in the Internet [9]. Its purpose is to be a guide for daily work and training. Furthermore, it is still recommended that the morphologic diagnosis of MDS should be achieved by a consensus of two experienced morphologists [3,6]. Our study underlines these problems of classification. The cells diagnosed as atypical immature myeloid precursors in the present study did not - on light microscopic examination reveal a Golgi apparatus, and would be therefore morphologically classified as blasts. However, the nucleus showed features more close to that of promyelocytes or nuclei of an "intermediate" state between blasts and promyelocytes.

Computerized texture analysis confirmed this subjective impression, since 4 features presented intermediate values between blasts and promyelocytes and 6 variables pointed out a similarity with nuclei of promyelocytes. Although the cytoplasm in these atypical cells still reveals characteristics of a blast, the nuclear structure is more similar to a promyelocyte, thus indicating an asynchronous maturation in MDS patients.

The existence of this intermediate maturation stage is of clinical importance. Cytologists basing their diagnosis mainly on cytoplasmic criteria will count these atypical immature cells together with blasts and thus increase the blast count. Other observers, emphasizing the similarity 
Table 5 Mean values of the variables in the granulocytic precursors in MDS

\begin{tabular}{|c|c|c|c|c|c|c|c|}
\hline $\begin{array}{l}\text { Nuclear morphometric or } \\
\text { texture feature }\end{array}$ & $\begin{array}{l}\text { MDS- } \\
\text { Blasts }\end{array}$ & $\begin{array}{l}P \text { MDS Blast vs } \\
\text { atyp }\end{array}$ & Atyp. & $\begin{array}{l}p \text { atyp. vs. } \\
\text { MDS Pro. }\end{array}$ & $\begin{array}{l}\text { MDS } \\
\text { Pro }\end{array}$ & $P$ global & $\begin{array}{c}\text { Classification of atypical myeloid } \\
\text { precursors }\end{array}$ \\
\hline 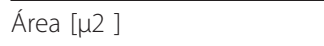 & 118.4 & 0.95 & 118.5 & 0.37 & 121.0 & 0.60 & (not defined) \\
\hline Perimeter & 598 & 0.01 & 628 & 0.004 & 656 & 0.00001 & Intermediate \\
\hline Form factor & 0.94 & $<0.0001$ & 0.85 & 0.0005 & 0.80 & 0.0001 & Intermediate \\
\hline Mean gray level & 125.1 & 0.0009 & 121.1 & 0.0227 & 118.6 & $<0.00001$ & intermediate \\
\hline SD* gray value & 9.1 & $<0.0001$ & 8.4 & 0.02 & 8.1 & 0.01 & Intermediate \\
\hline Haralick's entropy & 7.65 & 0.11 & 7.59 & 0.083 & 7.52 & 0.01 & (not defined) \\
\hline Inertia & 3.67 & 0.0038 & 3.39 & 0.095 & 3.28 & 0.0001 & close to MDS Pro. \\
\hline Local homogeneity & 0.553 & 0.32 & 0.555 & 0.23 & 0.558 & 0.12 & (not defined) \\
\hline Energy & 6749 & 0.00003 & 5748 & 0.39 & 5595 & $<0.0001$ & close to MDS Pro. \\
\hline Contrast & 3.67 & 0.0038 & 3.39 & 0.095 & 3.28 & 0.0001 & close to MDS Pro. \\
\hline Diagonal moment & 17.4 & 0.00058 & 16.1 & 0.098 & 15.6 & $<0.0001$ & close to MDS Pro. \\
\hline $\begin{array}{l}\text { Cluster prominence } \\
\left(10^{-5}\right)\end{array}$ & 3.17 & 0.021 & 2.39 & 0.51 & 2.19 & 0.018 & close to MDS Pro. \\
\hline$F D^{* * * *}$ & 2.1225 & 0.0015 & 2.1183 & 0.82 & 2.1180 & 0.0015 & close to MDS Pro. \\
\hline$R 2^{* * * * *}$ & 0.99819 & 0.026 & 0.99807 & 0.65 & 0.99809 & 0.068 & (not defined) \\
\hline
\end{tabular}

* atyp. = immature atypical myeloid precursors; ${ }^{* *}$ pro. $=$ promyelocyte; ${ }^{* * *} \mathrm{SD}=$ Standard deviation of gray value levels, ${ }^{* * * *} \mathrm{FD}=$ fractal dimension, ${ }^{* * * * *} 2$ goodness-of-fit of the fractal dimension.

of the nuclear features, might count them together with promyelocytes, or count them separately, thus diminishing the blast count. This may imply in a different classification for the patient.

The BM blast count is considered very important for the classification of MDS in the revised WHO classification [7] as well as for the determination of the IPSS and WPSS scores $[2,31,32]$. Furthermore, the blast count is considered to be an independent prognostic feature of utmost importance in MDS [2,6,7,33,35-37]. Therefore, additional pathophysiological and molecular studies should be performed in order to investigate whether these atypical precursor cells should not be counted as blasts, as suggested by our investigation.

\section{Acknowledgements}

K. Metze is Professor, Postgraduate Courses in Pathophysiology and Medical Sciences, Faculty of Medicine, State University of Campinas and is researcher of the National Research Council (CNPq).

RL Adam is Research Associate, Institute of Computing, State University of Campinas

I. Lorand-Metze is Professor in Hematology, Department of Internal Medicine, Faculty of Medicine, State University of Campinas, and is researcher of the National Research Council (CNPq).

This investigation was supported by the São Paulo Research Foundation FAPESP (project 2007/52015-0) and the National Council of Technological and Scientific Development CNPq (projects 479074/2008-9 and 307270/ 2010-6 )

\section{Author details}

'Department of Internal Medicine, Faculty of Medical Sciences, State University of Campinas, Rua Tessalia Vieira de Camargo 126, 13083-887, Campinas, Brazil. ${ }^{2}$ Institute of Computing, State University of Campinas, Av. Albert Einstein 1251, 13083-852, Campinas, Brazil. ${ }^{3}$ Department of Pathology,
Faculty of Medical Sciences, State University of Campinas, Rua Tessalia Vieira de Camargo 126, 13083-887, Campinas, Brazil.

\section{Authors' contributions}

JRV: collected all the clinical data, selected the material, classified the cells, acquired and segmented the cell images and reviewed the literature. RLA: developed the segmentation software and made all the computational analysis. ILM: provided the conception and design of the study, microscopic analysis, classification of the cells, drafting of the manuscript, and final approval. KM: participated in the study design, performed the statistical analyses and interpretation of the data, and made the critical revision of the text.

This study is part of a master thesis of JRV (Postgraduate Course in Medical Pathophysiology, FCM, University of Campinas) with ILM as principal advisor and KM as co-advisor. All authors have read and approved the manuscript.

\section{Competing interests}

The authors declare that they have no competing interests.

Received: 3 August 2011 Accepted: 29 September 2011 Published: 29 September 2011

\section{References}

1. Bennett JM, Catovsky D, Daniel MT, Flandrin G, Galton DA, Gralnick HR, Sultan C: Proposals for the classification of the myelodysplastic syndromes. Br J Haematol 1982, 51:189-99.

2. Greenberg P, Cox C, LeBeau MM, Fenaux P, Morel P, Sanz G, Sanz M, Vallespi T, Hamblin T, Oscier D, Ohyashiki K, Toyama K, Aul C, Mufti G, Bennett JM: International scoring system for evaluation in MDS. Blood 1997, 89:2079-88.

3. Haferlach T, Bacher U, Kern W, Schnittger S, Gassmann W, Haferlach C: A comprehensive approach to the diagnosis of MDS after triage by morphology towards cytogenetics and other techniques. Cancer Treat Rev 2007, 33:S31-S41.

4. Lorand-Metze I, Pinheiro MP, Ribeiro E, de Paula EV, Metze K: Factors influencing survival in myelodysplastic syndromes in a Brazilian population: Comparison of FAB and WHO classifications. Leuk Res 2004, 28:587-594.

5. Ribeiro E, Lima CSP, Metze K, Lorand-Metze I: Flow cytometric analysis of the expression of Fas/Fasl in bone marrow CD34+ cells in 
myelodysplastic syndromes: relation to disease progression. Leuk \& Lymph 2004, 45:309-313.

6. Valent $P$, Horny HP, Bennett JM, Fonatsch C, Germing U, Greenberg P, Haferlach T, Haase D, Kolb HJ, Krieger O, Loken M, van de Loosdrecht A, Ogata K, Orfao A, Pfeilstöcker M, Rüter B, Sperr WR, Stauder R, Wells DA: Definitions and standards in the diagnosis and treatment of the myelodysplastic syndromes: Consensus statements and report from a working conference. Leuk Res 2007, 31:727-39.

7. Swerdlow SH, Campo E, Harris NL, Jaffe ES, Pileri SA, Stein H, Thiele J, Vardiman JW: WHO classification of tumors of haematopoietic and lymphoid tissues. IARC press Lyon, France; 2008, 18-30.

8. Goasguen JE, Bennett J, Bain B, Brunning R, Vallespi MT, Cox C, Mufti G: New definitions for blast cells in AML and MDS with validation by virtual microscopy [abstract]. Leuk Res 2007, 31(suppl 1):S25.

9. Zini G, Bain B, Castoldi G, Cortez J, Csomor J, Faber E, Giagounidis A, Haferlach T, Kacirkova P, Lewandowski K, Liso V, Matutes E, Maynadiè M, Meletis J, Powit A, Ribeiro MC, Sreter L, Tichelli A, Vallespi T, van't Veer MB, Woessner S, Béné MC: European Leukemianet (ELN) project Diagnostic Platform (WP10): final results of the first study of the European Morphology Consensus Panel [abstract]. Blood 2008, 112:1645.

10. Wienert S, Beil M, Saeger K, Hufnagl P, Schrader T: Integration and acceleration of virtual microscopy as the key to successful implementation into the routine diagnostic process. Diagn Pathol 2009, $9: 4,3$

11. Izadi-Mood N, Yarmohammadi M, Ahmadi SA, Irvanloo G, Haeri H, Meysamie AP, Khaniki M: Reproducibility determination of WHO classification of endometrial hyperplasia/well differentiated adenocarcinoma and comparison with computerized morphometric data in curettage specimens in Iran. Diagn Pathol 2009, 4:10.

12. Jondet M, Agoli-Agbo R, Dehennin L: Automatic measurement of epithelium differentiation and classification of cervical intraneoplasia by computerized image analysis. Diagn Pathol 2010, 5:7.

13. Roa-Peña L, Gómez F, Romero E: An experimental study of pathologist's navigation patterns in virtual microscopy. Diagn Pathol 2010, 5:71.

14. Kayser K, Görtler J, Borkenfeld S, Kayser G: Interactive and automated application of virtual microscopy. Diagn Pathol 2011, 6(Suppl 1):S10.

15. Baak JP, Snijders W, van Diermen B, van Diest PJ, Diepenhorst FW, Benraadt J: Prospective multicenter validation confirms the prognostic superiority of the endometrial carcinoma prognostic index in international Federation of gynecology and obstetrics stage 1 and 2 endometrial carcinoma. J Clin Oncol 2003, 21:4214-4221.

16. Ferreira RC, de Matos PS, Adam RL, Leite NJ, Metze K: Application of the Minkowski-Bouligand fractal dimension for the differential diagnosis of thyroid follicular neoplasias. Cell Oncol 2006, 28:331-33.

17. Mello MRB, Metze K, Adam RA, Pereira FG, Magalhäes MG, Machado CG Lorand-Metze I: Phenotypic subtypes of acute lymphoblastic leukemia associated with different nuclear chromatin texture. Anal Quant Cytol Histol 2008, 30:175-84.

18. Bedin V, Adam RL, Sá BCS, Landman G, Metze K: Fractal dimension is an independent prognostic factor for survival in melanoma. BMC Cancer 2010, 10:260.

19. Metze K, Lorand-Metze I, Leite NJ, Adam RL: Goodness-of-fit of the fractal dimension as a prognostic factor. Cell Oncol 2009, 31:503-504.

20. Ferro DP, Falconi MA, Adam RL, Ortega MM, Lima CSP, de Souza CA, Lorand-Metze I, Metze K: Fractal Characteristics of May-Grünwald-Giemsa stained Chromatin are Independent Prognostic Factors for Survival in Multiple Myeloma. PLoS One 2011, 6(6):e20706.

21. Mello MLS, Vidal BC, Russo IH, Lareef MH, Russo J: DNA content and chromatin texture of human breast epithelial cells transformed with 17beta-estradiol and the estrogen antagonist ICI 182,780 as assessed by image analysis. Mutat Res-Rev Mutat 2007, 617:1-7.

22. Serrano D, Gandini S, Mariani L, Bonanni B, Santinelli A, Guerrieri-Gonzaga A, Pelosi G, Cassano E, Montironi R, Decensi A: Computer-assisted image analysis of breast fine needle aspiration in a randomized chemoprevention trial of fenretinide vs. placebo in HRT users. Breast 2008, 17:91-97.

23. Kortenhorst MSQ, Isharwal S, Van Diest PJ, Chowdhury WH, Marlow C, Carducci MA, Rodriguez R, Veltri RW: Valproic acid causes dose- and timedependent changes in nuclear structure in prostate cancer cells in vitro and in vivo. Mol Cancer Ther 2009, 8:802-08.
24. Yatouji S, El-Khoury V, Trentesaux C, Trussardi-Regnier A, Benabidet R, Bontems F, Dufer J: Differential modulation of nuclear texture, histone acetilation and MDR1 gene expression in human drug-sensitive and resistant OV1 cell lines. Int J Oncol 2007, 30:1003-09.

25. Kayser K, Hoshang SA, Metze K, Goldmann T, Vollmer E, Radziszowski D, Kosjerina Z, Mireskandari M, Kayser G: Texture and object-related automated information analysis in histological still images of various organs. Anal Quant Cytol Histol 2008, 30:323-35.

26. Metze K: Fractal dimension of chromatin and cancer prognosis. Epigenomics 2010, 2:601-604.

27. Metze K, Adam RL, Leite NJ: Changes of texture features due to image compression. Diagn Pathol 2010, 5(Suppl 1):S15.

28. Metze K, Adam RL, Ferreira RC: Robust variables in texture analysis. Pathology 2010, 42:609-610.

29. Adam RL, Silva RC, Pereira FG, Leite NJ, Lorand-Metze I, Metze K: The fractal dimension of nuclear chromatin as a prognostic factor in acute precursor B lymphoblastic leukemia. Cell Oncol 2006, 28:55-59.

30. Melnick AM: Epigenetics in AML. Best Pract Res Clin Haematol 2010, 23:463-468.

31. De Capoa A, Febbo FR, Giovannelli F, Niveleau A, Zardo G, Marenzi S, Caiafa P: Reduced levels of poly (ADP-ribosyl)ation result in chromatin compaction and hypermethylation as shown by cell-by-cell computerassisted quantitative analysis. FASEB J 1999, 13:89-93.

32. Reis-Alves SC, Traina I, Saad ST, Metze K, Lorand-Metze I: The impact of several phenotypic features at diagnosis on survival of patients with myelodysplastic syndromes. Neoplasma 2010, 57:530-536.

33. Bernasconi P: Molecular pathways in myelodysplastic syndromes and acute myeloid leukemia: relationships and distinctions-a review. $\mathrm{Br} J$ Haematol 2008, 142:695-708.

34. Lorand-Metze I, Ribeiro E, Lima CSP, Batista LS, Metze K: Detection of hematopoietic maturation abnormalities by flow cytometry in myelodysplastic syndromes and its utility for the differential diagnosis with non-clonal disorders. Leuk Res 2007, 31:147-155.

35. Vollmer RT: Blast counts in bone marrow aspirate smears. Am J Clin Pathol 2009, 131:183-88.

36. Mufti GJ, Bennett J, Goasguen J, Bain BJ, Baumann I, Brunning R, Cazzola M Fenaux P, Germing U, Hellström-Lindberg E, Jinnai I, Manabe A, Matsuda A, Niemeyer CM, Sanz G, Tomonaga M, Vallespi T, Yoshimi A: Diagnosis and classification of myelodysplastic syndrome: International Working Group on Morphology of myelodysplastic syndrome consensus proposals for the definition and enumeration of myeloblasts and ring sideroblasts. Haematologica 2008, 93:1712-1717.

37. Schanz J, Steidl C, Fonatsch C, Pfeilstöcker M, Nösslinger T, Tuechler $H_{\text {, }}$ Valent P, Hildebrandt B, Giagounidis A, Aul C, Lübbert M, Stauder r, Krieger O, Garcia-Manero G, Kantarijan H, Germing U, Haase D, Estey E: Coalesced multicentric analysis of 2,351 patients with myelodysplastic syndromes indicates an underestimation of poor-risk cytogenetics of myelodysplastic syndromes in the international prognostic scoring system. J Clin Oncol 2011, 29:1963-1970.

doi:10.1186/1746-1596-6-93

Cite this article as: Vido et al: Computerized texture analysis of atypical immature myeloid precursors in patients with myelodysplastic syndromes: an entity between blasts and promyelocytes. Diagnostic Pathology 2011 6:93.

\section{Submit your next manuscript to BioMed Central and take full advantage of:}

- Convenient online submission

- Thorough peer review

- No space constraints or color figure charges

- Immediate publication on acceptance

- Inclusion in PubMed, CAS, Scopus and Google Scholar

- Research which is freely available for redistribution 